\title{
Comparison of Acoustic and Stroboscopic Findings and Voice Handicap Index between Allergic Rhinitis Patients and Controls
}

\author{
Eltaf Ayça Özbal Koç ${ }^{1}$, Bülent Koç², Selim Erbek ${ }^{1}$ \\ ${ }^{1}$ Department of Otorhinolaryngology, Başkent University Faculty of Medicine, Ankara, Turkey \\ ${ }^{2}$ Department of Otorhinolaryngology, Pendik Hospital, İstanbul, Turkey
}

Background: In our experience Allergic Rhinitis (AR) patients suffer from voice problems more than health subjects.

Aims: To investigate the acoustic analysis of voice, stroscopic findings of larynx and Voice Handicap Index scores in allergic rhinitis patients compared with healthy controls.

Study Design: Case-control study.

Methods: Thirty adult patients diagnosed with perennial allergic rhinitis were compared with 30 age- and sex-matched healthy controls without allergy. All assessments were performed in the speech physiology laboratory and the testing sequence was as follows: 1. Voice Handicap Index (VHI) questionnaire, 2. Laryngovideostroboscopy, 3. Acoustic analyses.
Results: No difference was observed between the allergic rhinitis and control groups regarding mean Maximum Phonation Time (MPT) values, Fo values, and stroboscopic assessment ( $p>0.05)$. On the other hand, mean VHI score $(p=0.001)$ and $s / z$ ratio $(p=0.011)$ were significantly higher in the allergic rhinitis group than in controls.

Conclusion: Our findings suggest that the presence of allergies could have effects on laryngeal dysfunction and voice-related quality of life.

Key Words: Allergic rhinitis, voice handicap index, dysphonia

\section{INTRODUCTION}

Allergic rhinitis (AR) is a worldwide health issue affecting $10 \%-25 \%$ of the population (1). AR has been intensely related with many chronic diseases such as asthma, rhinosinusitis, and ear infections (2). AR affects everyday activities, and is not fatal disease so its morbidity is often underestimated. The problems caused by AR are often worsened by the variety of complaints involved (3). Voice disorders have been commonly associated with respiratory allergy (3). In a population of 80 AR cases, Baker et al. (4) found voice disorders in $44.75 \%$ of the patients.

The nose and other tissues of the supraglottic vocal tract are responsible for vocal quality and perceived characters of speech sounds $(5,6)$. Niedzielska et al. (7) studied the acoustic estimation of voice and stated that in patients with AR, the mean Jitter and Shimmer values were higher than in the control group; however, the difference did not reach statistical significance. Simberg et al. (5) studied the relationship be- tween vocal symptoms and allergy, and stated that vocal fold injuries, such as haemorrhage and mucosal tears, may significantly accompany concurrent reflux, asthma or allergy.

Although there is a lot of literature dealing with the nasal symptoms of AR, comparatively little information has been published on the effects of AR on voice and speech. The aim of the present study was to investigate the acoustic and stroboscopic findings of the larynx and Voice Handicap Index (VHI) scores in patients with AR and to compare them with healthy controls.

\section{MATERIAL AND METHODS}

\section{Study design}

The present study was approved by the Başkent Institutional Review Board (KA12/223). Written informed consent was obtained from all participants. Thirty adult patients diagnosed with perennial AR between February 2013 and November

Address for Correspondence: Dr. Eltaf Ayça Özbal Koç, Department of Otorhinolaryngology, Başkent University Faculty of Medicine, Ankara, Turkey Phone: +90 5327782747 e-mail: ozbalayca@yahoo.com

Received: 13.06.2014 Accepted: 02.10.2014 • DOI: 10.5152/balkanmedj.2014.14511 
2013 were compared with 30 age- and sex-matched healthy control subjects without allergy. To qualify for enrolment, patients with AR needed to have a positive skin prick test result. The healthy controls without rhinitis and allergy symptoms were randomly selected among patients admitted to the dental clinic of our centre for routine dental examination. None of the controls were aware of having any allergy and their skin prick test results were negative.

Exclusion criteria for the study and the control groups were as follows: age below 17 or above 70 years, nasal problems (nasal polyposis, severe nasal deviation etc.), pregnancy, smoking, history of laryngeal pathology or laryngeal surgery, diagnosed reflux or gastroesophageal reflux (GER), patients with asthma, patients who received systemic corticosteroids, systemic antihistamines, decongestants or leukotriene modifiers in the past six months or immunotherapy within the past two years.

\section{Skin prick test}

All subjects underwent skin prick testing performed on the forearm. Saline solution was used as the negative control and histamine as the positive control. The presence of allergy was assessed through skin-prick test (Alk-Abello S.A., Madrid, Spain). A positive response was judged by a wheal diameter at least $3 \mathrm{~mm}$ larger than the wheal diameter of the negative control. Skin-test responsiveness was assured with placement of the positive control.

\section{Outcome parameters}

All assessments occurred in the speech physiology laboratory in our clinic. The testing sequence was as follows: 1 . VHI questionnaire, 2. Laryngovideostroboscopy, 3. Acoustic analyses.

1. Voice Handicap Index: The Turkish version of a validated questionnaire, the Voice Handicap Index (VHI), was performed for all patients $(8,9)$. The VHI consists of 10 questions on emotional, functional and physical aspects of voice. Each question is graded on a 5-point scale $(0=$ Never, $1=$ Almost Never, $2=$ Sometimes, $3=$ Almost Always, $4=$ Always). The total score ranges from 0 (unaffected) to 40 (severely affected).

2. Laryngovideostroboscopy: Larynx examination is made by using a $70^{\circ}$ magnifying laryngoscope (Richard Wolf, $\mathrm{GmbH}$, Knittlingen, Germany). Vibratory behaviour was assessed by a Digital Strobe View 5570 stroboscope (Richard Wolf, GmbH, Knittlingen, Germany). Closure level, amplitude, vocal fold edge, supraglottic involvement, mucosal wave, non-vibrating portion and closure phase were observed. The results were marked on the "Stroboscopic Assessment Form" (10). Endolaryngeal secretion, excessive mucus and oedema were also noted. As for the aerodynamic assessment, maximum phonation time (MPT) was determined by measuring the duration of the /a/ vowel after maximum inspiration. MPT was elicited over three trials, the longest of which was considered definitive. The $s / z$ ratio was calculated by measuring the MPT of single consonants $/ \mathrm{s} /$ and $/ \mathrm{z} /$ in two separate breaths. The best $/ \mathrm{s} /$ and $/ \mathrm{z} / \mathrm{effort}$ of at least three attempts at each was used to obtain the ratio.

3. Acoustic analysis: Multi-Dimensional Voice Program (MDVP, model 5105, version 2.5, Kay Elemetrics Corp, Lincoln Park, NJ, USA) with Multi-Speech software (Model 3700, version 2.4, Kay Elemetrics Corp, Lincoln Park, NJ, USA) was coupled to a microphone (AKG, Model C-1000, Nashville, Tennessee, USA), with a standard sound board (Creative Sound Blaster Audigy 2ZS, Creative Technology Ltd, Singapore). The recordings were performed in a silent room by means of a microphone at a stable mouth-to-microphone distance of 15 $\mathrm{cm}$. The patients were educated to sustain the vowels at a comfortable pitch and level of loudness three times before recording in order to obtain maximum phonation during recording. The acoustic analysis was performed by measuring the pitch levels. The habitual pitch level was determined using the strobe unit as the patients read the words "Adanayaaaaa" and prolonged the final vowel /a/ (11).

\section{Statistical analysis}

Data were analysed using the Statistical Package for Social Sciences 15.0 for Windows (SPSS Inc., Chicago, IL, USA). Parametric tests were applied to data of normal distribution and non-parametric tests were applied to data of questionably normal distribution. The Student-t test, Chi-square test, Fisher's Exact test and Continuity (yates) correction test were used to analyse the differences between two groups. Data are expressed as mean $\pm \mathrm{SD}$. All differences associated with a chance probability of 0.05 or less were considered statistically significant. The power analysis of the study for the continuous variables for $\mathrm{s} / \mathrm{z}$ ratio was $74 \%$ (the standard deviation was 0.175 , hypothesis was two-sided, and the $\alpha$ value was 0.05 ). Since more than $20 \%$ of the cells in the expected frequencies less than 5 in some of the cross table, the Yates correction was made (number was less than 30 ).

\section{RESULTS}

Thirty patients with AR (17 females, 13 males) and 30 sexand age-matched healthy controls ( 17 females, 13 males) met the eligibility criteria for the study. The mean age was $32.70 \pm 10.68$ 
years for the AR group and $34.87 \pm 9.40$ years for the control group. All patients and controls completed the study.

The mean VHI score of the AR group was significantly higher than those of the control group $(\mathrm{p}=0.001)$. No significant differences were found between the AR group and control group in either mean MPT values $(\mathrm{p}=0.083)$ or mean Fo values $(\mathrm{p}=0.825)$. The $\mathrm{s} / \mathrm{z}$ ratio was significantly higher in the AR group than the control group $(p=0.011)$ (Table 1). Habitual pitch and MPT values were within the normal limits for both groups.

As for the stroboscopic assessment, no significant differences were found between the AR group and control group in closure level $(\mathrm{p}=1.000)$, vocal fold edge $(\mathrm{p}=0.770)$, supra-

TABLE 1. The mean values of maximum phonation time, $\mathrm{s} / \mathrm{z}$ ratio, Fo, and Voice Handicap Index in AR group and Control group

\begin{tabular}{lccc}
\hline & $\begin{array}{c}\text { AR group } \\
\text { mean } \pm \text { SD }\end{array}$ & $\begin{array}{c}\text { Control group } \\
\text { mean } \pm \text { SD }\end{array}$ & p value \\
\hline Maximum phonation time & $16.43 \pm 2.81$ & $17.77 \pm 3.03$ & 0.083 \\
s/z Ratio & $1.20 \pm 0.19$ & $1.08 \pm 0.16$ & 0.011 \\
Fo & $182.27 \pm 51.50$ & $184.97 \pm 42.31$ & 0.825 \\
Voice Handicap Index & $15.40 \pm 5.33$ & $8.33 \pm 3.29$ & 0.001 \\
\hline Student $\mathrm{t}$ test; $\mathrm{p}<0.05 ; \mathrm{p}<0.01$ & & & \\
SD: standard deviation; AR: allergic rhinitis & &
\end{tabular}

TABLE 2. The stroboscopic findings of AR + and Control groups

\begin{tabular}{|c|c|c|c|c|}
\hline & AR group & $\begin{array}{c}\text { Control group } \\
\mathrm{n}(\%)\end{array}$ & $\mathrm{n}(\%)$ & $\mathrm{p}$ value \\
\hline \multirow[t]{2}{*}{${ }^{+++}$Closure level } & 0 & $28(93.3 \%)$ & $28(93.3 \%)$ & 1.000 \\
\hline & 1 & $2(6.7 \%)$ & $2(6.7 \%)$ & \\
\hline \multirow[t]{2}{*}{${ }^{++}$Vocal fold edge } & 0 & $21(70.0 \%)$ & $23(76.7 \%)$ & 0.770 \\
\hline & 1 & $9(30.0 \%)$ & $7(23.3 \%)$ & \\
\hline \multirow[t]{3}{*}{${ }^{+}$Supraglottic in involvemen } & 0 & $9(30.0 \%)$ & $12(40.0 \%)$ & 0.293 \\
\hline & 1 & $19(63.3 \%)$ & $18(60.0 \%)$ & \\
\hline & 2 & $2(6.7 \%)$ & $0(0 \%)$ & \\
\hline \multirow[t]{2}{*}{${ }^{++}$Amplitude } & 0 & $20(66.7 \%)$ & $22(73.3 \%)$ & 0.778 \\
\hline & 1 & $10(33.3 \%)$ & $8(26.7 \%)$ & \\
\hline \multirow[t]{3}{*}{${ }^{+}$Mucosal wave } & 0 & $20(66.7 \%)$ & $23(76.7 \%)$ & 0.320 \\
\hline & 1 & $8(26.7 \%)$ & $7(23.3 \%)$ & \\
\hline & 2 & $2(6.7 \%)$ & $0(0 \%)$ & \\
\hline \multirow[t]{2}{*}{${ }^{++}$Non-vibrating portion } & 0 & $27(90.0 \%)$ & $27(90.0 \%)$ & 1.000 \\
\hline & 1 & $3(10.0 \%)$ & $3(10.0 \%)$ & \\
\hline \multirow[t]{4}{*}{${ }^{+}$Closure phase } & None & $25(83.3 \%)$ & $27(90.0 \%)$ & 0.492 \\
\hline & Bowing & $3(10.0 \%)$ & $1(3.3 \%)$ & \\
\hline & Irregular & $1(3.3 \%)$ & $2(6.7 \%)$ & \\
\hline & Post chick & $1(3.3 \%)$ & $0(0 \%)$ & \\
\hline
\end{tabular}

${ }^{+}$Pearson Chi-Square test; ${ }^{++}$Continuity (Yates) correction; ${ }^{++}$Fisher's Exact test AR: allergic rhinitis glottic involvement $(\mathrm{p}=0.293)$, amplitude $(\mathrm{p}=0.778)$, mucosal wave $(\mathrm{p}=0.320)$, non-vibrating portion $(\mathrm{p}=1.000)$, and closure phase $(\mathrm{p}=0.492)$ (Table 2).

\section{DISCUSSION}

In the present study, we investigated the acoustic and stroboscopic findings of the larynx and VHI scores in AR patients and compared with normal healthy subjects. The present study showed that no difference was found between the AR and control groups regarding mean MPT values, Fo values, and stroboscopic assessment. However, the mean VHI score and $\mathrm{s} / \mathrm{z}$ ratio were significantly higher in the AR group.

In the event of AR, several mechanisms are responsible for dysphonia. First, the hypersecretion of the nasal glands causes postnasal drainage: the consequences are cough, throat clearing, and dysphonia (12). Secondly, the rhino-laryngeal reflexes (sympathetic and parasympathetic fibres demonstrated in the musculus vocalis) secondary to AR may contribute to the presence of dysphonia (13). Thirdly, specific receptors sensitive to negative pressure in the nasal cavity and in the pharynx may increase the muscular activity of the posterior cricoarytenoid muscle $(14,15)$. Fourthly, serous otitis diagnosed in nearly $66 \%$ of children affected by AR may induce vocal abuse (4). Finally, Gastroesophageal Reflux (GER) is a frequent finding in laryngeal disorders (16). In the present study, patients with GER were excluded from the study.

In the present study, we revealed that patients with AR had a higher prevalence of dysphonia than controls. This is consistent with the findings of previous studies which showed that singers with voice problems were more likely to have AR and that patients with AR who needed allergen immunotherapy were more likely to have dysphonia $(12,17)$.

The high prevalence of AR in cases with voice disorders causes difficulties in identifying the particular pathogenetic role of AR as an independent variable. Physical examination findings in patients with AR may be normal or nonspecific, such as oedema, redness, or thick mucus labelled as functional dysphonia (14). In the present study, no significant differences was found between the AR group and control group in stroscobic findings such as closure level, vocal fold edge, supraglottic involvement, amplitude, mucosal wave, non-vibrating portion, and closure phase. However, apart from these findings, it is well known that excess mucous in the larynx causes vocal symptoms. Duncan et al. (18) examined patients with allergy and stated that nearly $33 \%$ exhibited laryngeal symptoms such as throat irritation, soreness, burning, and laryngitis. Also they noted that after medication $94 \%$ of these patients experienced improvements in their symptoms. Jackson-Menaldi et al. (19) 
described 17 allergic patients who complained of concomitant laryngeal symptoms and revealed that vocal fold oedema was a common pathological feature among these patients.

Patients with AR have increased excretion of mucus from the nose. Jackson-Menaldi et al. (19) and Sala et al. (20) stated that patients with allergy frequently had thick secretions, hoarseness, and laryngeal oedema/erythema. Unfortunately, these findings were not specific enough to reveal a direct relationship between allergy and laryngeal findings. In the present study, eight of the 30 patients with AR had thick secretions which were thought to be from postnasal drips.

The Voice Handicap Index is a validated tool measuring the impact of vocal problems on quality of life (21). Millqvist et al. (22) and Krouse et al. (23) studied patients gropus with allergy, and both showed the negative effect of allergies on voice-related quality of life. Consistent with these studies, the two groups were significantly different from one another on total VHI scores in our study.

In 1971, Boone, who first described the s/z ratio, also hypothesised that cases with normal vocal folds could be expected to prolong the voiceless $/ \mathrm{s} /$ and the voiced $/ \mathrm{z} /$ phonemes for approximately the similar duration of time so the $\mathrm{s} / \mathrm{z}$ ratio is expected 1 (24). After that report, it was estimated that patients with laryngeal pathologies would have difficulty prolonging the voiced sound $/ \mathrm{z} /$ for the same length of time as voiceless /s/ in many studies (3). Therefore, the $\mathrm{s} / \mathrm{z}$ ratio is estimated to be longer then 1.2-1.4 in laryngeal pathologies. In the present study, the $\mathrm{s} / \mathrm{z}$ ratio was significantly higher in the AR group than in the control group; however, the mean value is within normal limits according to the previously described values. Our finding suggested that patients with AR had laryngeal pathology, so they had difficulty in prolonging the sound $/ \mathrm{z} /$, although the mean $\mathrm{s} / \mathrm{z}$ ratio was within the normal limits.

In conclusion, our study demonstrated a significant difference in the mean VHI values and the mean $\mathrm{s} / \mathrm{z}$ ratio between AR patients and healthy controls, indicating a relationship between allergy and dysphonia. Allergy should be considered a potential cause of nonorganic dysphonia and laryngeal symptoms in the diagnostic process.

Ethics Committee Approval: Ethics committee approval was received for this study from the ethics committee of Başkent University.

Informed Consent: Written informed consent was obtained from patients
who participated in this study.

Peer-review: Externally peer-reviewed.

Author contributions: Concept - E.A.Ö.K., B.K., S.E.; Design - E.A.Ö.K.; Supervision - E.A.Ö.K., B.K.,S.E.; Resource - E.A.Ö.K., B.K., S.E.; Materials - E.A.Ö.K., B.K.,S.E.; Data Collection\&/or Processing - E.A.Ö.K., B.K., S.E.; Analysis\&/or Interpretation - E.A.Ö.K., B.K., S.E.; Literature Search
- E.A.Ö.K., B.K., S.E.; Writing - E.A.Ö.K., B.K., S.E.; Critical Reviews E.A.Ö.K., B.K., S.E.

Conflict of Interest: No conflict of interest was declared by the authors.

Financial Disclosure: The authors declared that this study has received no financial support.

\section{REFERENCES}

1. Ologe FE, Adebola SO, Dunmade AD, Adeniji KA, Oyejola BA. Symptom score for allergic rhinitis. Otolaryngol Head Neck Surg 2013;148:557-63.[CrossRef]

2. Izquierdo-Domínguez A, Valero AL, Mullol J. Comparative analysis of allergic rhinitis in children and adults. Curr Allergy Asthma Rep 2013;13:142-51.[CrossRef]

3. Roth DF, Ferguson BJ. Vocal allergy: Recent advances in understanding the role of allergy in dysphonia. Curr Opin Otolaryngol Head Neck Surg 2010;18:176-81.[CrossRef]

4. Baker BM, Baker CD, Thanh HA. Vocal quality, articulation and audiological characteristics of children and young adults with diagnosed allergies. Ann Otol Rhinol Laryngol 1982;91:277-80.[CrossRef]

5. Simberg S, Sala E, Tuomainen J, Rönnemaa AM. Vocal symptoms and allergy--a pilot study. J Voice 2009;23:136-9. [CrossRef]

6. Gerek M, Durmaz A, Aydin U, Birkent H, Hidir Y, Tosun F. Relationship between nasal valve changes and nasalance of the voice. Otolaryngol Head Neck Surg 2012;147:98-101.[CrossRef]

7. Niedzielska G. Acoustic estimation of voice when incorrect resonance function of the nose takes place. Int J Pediatr Otorhinolaryngol. 2005;69:1065-9.[CrossRef]

8. Kiliç MA, Okur E, Yildirim I, Oğüt F, Denizoğlu I, Kizilay A, et al. Reliability and validity of the Turkish version of the Voice Handicap Index. Kulak Burun Bogaz Ihtis Derg 2008;18:139-47.

9. Jacobson GH. The voice handicap index (VHI): Development and validation. Am J Speech Lang Pathol 1997;6:66-9. [CrossRef]

10. Hirano M, Bless MD. Videostroboscopic examination of the larynx. San Diego: Singular Publishing; 1993.p.90.

11. Andrews ML. Manuel of voice treatment pediatrics through geriatrics. San Diego: Singular Publishing; 1997.p.32-61.

12. Hamdan AL, Sibai A, Youssef M, Deeb R, Zaitoun F. The use of a screening questionnaire to determine the incidence of allergic rhinitis in singers with dysphonia. Arch Otolaryngol Head Neck Surg 2006;132:547-9.[CrossRef]

13. Turley R, Cohen SM, Becker A, Ebert CS Jr. Role of rhinitis in laryngitis: another dimension of the unified airway. Ann Otol Rhinol Laryngol 2011;120:505-10.[CrossRef]

14. Sant'Ambrogio G, Mathew OP, Fisher JT, Sant'Ambrogio FB. Laryngeal receptors responding to transmural pressure, airflow and local muscle activity. Respir Physiol 1983;54:317-30.[CrossRef]

15. Lauriello M, Angelone AM, Businco LD, Passali D, Bellussi LM, Passali FM. Correlation between female sex and allergy was significant in patients presenting with dysphonia. Acta Otorhinolaryngol Ital 2011;31:161-6.

16. Randhawa PS, Mansuri S, Rubin JS. Is dysphonia due to allergic laryngitis being misdiagnosed as laryngopharyngeal reflux? Logoped Phoniatr Vocol 2010;35:1-5.[CrossRef]

17. Simberg S, Sala E, Tuomainen J, Rönnemaa AM. Vocal symptoms and allergy - a pilot study. J Voice 2009;23:136-9.[CrossRef]

18. Duncan RB, Duncan TD. Otolaryngeal allergy in Wellington 19711975. N Z Med J 1977;85:45-8. 
19. Jackson-Menaldi CA, Dzul AI, Holland RW. Allergies and vocal fold edema: a preliminary report. $J$ Voice 1999;13:113-22.[CrossRef]

20. Sala E, Hytonen M, Tupasela O, Estlander T. Occupational laryngitis with immediate allergic or immediate type specific chemical hypersensitivity. Clin Otolaryngol Allied Sci 1996;21:42-8.[CrossRef]

21. Cohen SM, Jacobson BH, Garrett CG, Noordzij JP, Stewart MG, Attia A, et al. Creation and validation of the Singing Voice Handicap Index. Ann Otol Rhinol Laryngol 2007;116:402-6.[CrossRef]
22. Millqvist E, Bende M, Brynnel M, Johansson I, Kappel S, Ohlsson AC. Voice change in seasonal allergic rhinitis. $J$ Voice 2008;22: 512-5.[CrossRef]

23. Krouse JH, Dworkin JP, Carron MA, Stachler RJ. Baseline laryngeal effects among individuals with dust mite allergy. Otolaryngol Head Neck Surg 2008;139:149-51.[CrossRef]

24. Boone DR. The voice and voice therapy. Englewood Cliffs, NJ: Prentice-Hall; 1971. 